\title{
MOBILE TECHNOLOGIES AND AUTHENTIC LEARNING IN THE PRIMARY SCHOOL CLASSROOM
}

\author{
Dr Kevin Burden and Dr Damian Maher
}

\section{Introduction:}

The use of mobile technologies, often referred to as m-learning, is increasing in many primary schools across the developed and developing world. In the developed world mobile devices such as iPads, tablets and smartphones are being used whilst in some parts of the developing world $\mathrm{XO}$ computers are being rolled out. Young people are also using mobile devices in greater numbers in their personal lives. In the United States for example, research conducted by Pew Research Centre found that in 2012,37\% of all youth aged between 12-17 years had smart phones which is up from just $23 \%$ in 2011 . Approximately $25 \%$ own a tablet device (Madden, et al, 2013). Younger children are also increasingly being provided with smart phones and tablets as well.

The significance of using mobile technologies lies in the new and unique affordances they offer learners beyond what is possible with traditional 'tethered' technologies such as the desktop computer (Traxler, 2007). "Mobile devices open up new opportunities for independent investigations, practical fieldwork, professional updating and on-the-spot access to knowledge" (Kukulska-Hulme and Traxler, 2005, p. 26).

The use of mobile devices allows pupils to learn in innovative and exciting ways. One of the different ways that mobile devices can support learning is the ability to provide for authentic learning experiences which includes access to realistic settings and activities. The ability to connect to experts via mobile technologies also provides for learning experiences that are more authentic.

The focus of this chapter is to examine both literature (theory) and practice associated with the innovative use of mobile technologies in primary/elementary schools and other associated educational settings. To begin, a brief outline of the literature is presented. Next, models that have been developed as a way of conceptualising mobile learning are examined. A case study on the use of mobile technologies is presented and then the practical and pedagogical considerations associated with implementing mobile technologies into the classroom are explored. In each of the four sections a task is provided to help you develop your understanding around the focus. 


\section{Objectives}

At the end of this chapter you should be able to:

- understand the various models that underpin the use of mobile technologies

- be aware of some of the pedagogical and logistical considerations of using mobile technologies.

- begin to implement the use of mobile technologies into you teaching practices

\section{The literature on mobile technologies}

A term that is sometimes used to describe the use of mobile technology is 'ubiquitous learning'. Some of the characteristics of this include:

- accessibility: The information is always available whenever the learners need to use it

- immediacy: The information can be retrieved immediately by the learners

- interactivity: The learners can interact with peers, teachers, and experts efficiently and effectively through different media

- context-awareness: The environment can adapt to the learners real situation to provide adequate information for the learners (Yahya, et al, 2010).

There are two other particular aspects to mobility as pointed out by Kinash, Brand, Trishita, and Kordyban (2011), which are that pupils have access to lightweight portable devices but also that there is continuous access to the Internet so that pupils can learn anywhere and anytime. This latter element is what is known as untethered and ubiquitous learning. By creating opportunities to learn anywhere anytime, home-school links can be strengthened. An issue here though is that often homes are much better equipped than schools with technology which can create a homeschool divide which according to Merchant (2007), is a cause for some concern.

Mobile learning technologies allow for a number of different affordances beyond a desktop computer. One of these affordances is personalised learning (Leadbetter, 2005; Kearney, et al, 2012). This allows teachers to be able to differentiate the curriculum more easily as well as differentiate for ability, creativity, and interests (Kearney and Maher, 2012). Another affordance of mobile technologies is their suitability for use in a variety of settings that traditionally have not been possible with desktop computers. Taking the laptop into the playground and on excursions allows students to gather information and record ideas using some of the inbuilt features of mobile technologies including cameras, audio recordings and video capture (Wishart and Triggs, 2010).

Mobile technologies can also be used effectively in more formal settings such as visits to museums or zoos for example (Vavoula, et al, 2009). A further affordance of mobile technologies is that they bring together both the means of capturing data as well as the means to 
then manipulate, construct and re-represent this information. This 'convergence of activity' allow pupils to produce work in a way that is easier for them to manage and understand. An example of this is where pupils can capture still or video footage and then use the inbuilt editing software to produce a multimodal finished text. Mobile devices can also interact with other devices to provide extra information for users such as in the use of $\mathrm{QR}$ codes and virtual environments. One such use, which is predicted by authors of the Horizon K-12 Report in the next few years is Augmented Reality, where information is layered onto an existing image (Johnson, et al, 2012). This has many educational possibilities both within and outside of the classroom.

\section{TASK 1: Surveying the pupils}

Survey the pupils in your class regarding their use of mobile technologies. Ask them:

- what type of mobile technologies, if any, they use?

- how often they use these technologies?

- what do they use these technologies for? (e.g. listening to music, using the internet etc).

- what sort of restrictions, if any, their parents put in place for their use?

Once you have this information consider how mobile devices might be effectively used in your classroom so that you can help to develop authentic learning experiences for your pupils. Also ask your pupils what types of activities they would like to undertake using mobile technologies related to classroom learning.

\section{Models available for using mobile technologies}

Various models have been developed to assist researchers and teachers understand how mobile devices, such as smartphones, can add value to the learning experience of young people (see for example, Danaher, et al, 2009; Klopfer, et al, 2002; Koole, et al, 2010; Motiwalla, 2007; Vavoula and Sharples, 2009). These models cover a number of common themes which include the aspect of mobility itself, the opportunity for greater learner autonomy and choice and collaboration (Kearney, et al, 2012). Some of these models focus on the pedagogical use and application of mobile devices whilst a larger number have tended to concentrate on the technical and design aspects of m-learning (Teall, et al, 2011).

As the field of m-learning matures and the user base grows it will become increasingly important for teachers to be aware of the emerging issues which shape the design of pedagogically valid learning activities when mobile devices are used. Koole and her colleagues (2010) have developed a model based on this premise which identifies three converging factors which 
support valid learning designs with mobile technologies. These include an awareness of the mobile device itself and its various affordances for learning (D); the characteristics of the learner including their previous experiences with technology $(\mathrm{L})$, and social aspects which include the rules for social interaction between individuals $(\mathrm{S})$. This model provides guidance for teachers who wish to design ecologically valid activities for m-learning. A similar model is currently under development in a joint Australia-UK project which seeks to support how teachers design meaningful activities which exploit the unique affordances of mobile devices (Kearney, et al, 2012). In this case the authors have identified collaboration, authenticity and personalisation as macro-level affordances of m-learning which are further subdivided into six separate strands which include agency, customisation, contextualisation, situatedness, conversation and datasharing.

Whilst each of these models have been developed originally with mobile phones in mind, many of the affordances and opportunities which they promise are transferable to the emerging tablet technologies such as the iPad which are being used in primary schools.

\section{TASK 2: Developing your own model of m-learning}

Have a go at developing a model drawing on the different elements of the models presented here as well as drawing on the literature. In doing this, also be guided by the information that you got from your pupils in the survey from TASK 1: Surveying the pupils. Consider the important elements that suit your pedagogical style.

The following case study highlights the use of iPads in a primary school in Australia where many of the features highlighted in the section above can be identified.

\section{Case Study: Strategies to achieve learning outcomes using mobile technologies}

The research study, which was conducted by one of the authors, examines the use of an iPad with a year three class to facilitate links beyond the classroom using video conferencing. The study illustrates how mobile technologies can be used to connect to spaces beyond classrooms, museums and other traditional connected spaces to experts.

The class was studying communities in the local area and an iPad was used to connect to the local council and to meals-on-wheels. An iPad was taken out to the setting and this was then connected to a computer in the classroom which in turn was connected to an IWB. 
In talking with staff at both locations, pupils were able to experience authentic learning opportunities with experts whom they might not ordinarily have been able to talk with. The meals-on-wheels visit demonstrated how mobile technologies can facilitate new experiences as the pupils were able to experience the kitchen and surrounding areas in person because of health restrictions.

The results show that whilst there were opportunities, there was a clear question-answer structure to the lessons. In this regard the lessons were not highly pupil-centred although the pupils did have the opportunity to ask relevant questions that they did want to ask beforehand. Another difficulty that was encountered in the project was for the pupils to be heard by the experts using the microphone on the computer. Often the teacher had to repeat the pupils' questions which made communication a little difficult at times. More work in the field is required to get this part of the process working satisfactorily.

\section{TASK 3: Developing a class based scenario}

In drawing on the ideas you developed from TASKS 1 and 2, develop your own class-based scenario and consider how you would implement the use of mobile technologies into your own teaching. Use the pupils from TASK 1 or ideally consider who your next class will be and try to develop a lesson or series of lessons using the mobile technologies available in your school.

\section{Practical implications for using and supporting mobile technologies in classrooms}

\section{Learning with others and through collaboration with mobile technologies}

The opportunities to support social and collaborative forms of learning through mobile technologies, build upon a considerable body of socio-cultural and situated learning theories (Pachler, et al, 2010) which have recently been confirmed in a number of meta-analyses of technology use in education (Higgins, et al, 2012; Luckin, et al, 2012 ). These studies suggest that mobile technology has the potential to support many of the more social forms of learning such as conversation (dialogical learning) and data sharing (Kearney, et al, 2012). The size and portability of mobile devices are ideal for collaborative activities such as group-work and sharing of data between users since they can be used spontaneously as and when the learner wishes to undertake this type of activity. A wide variety of Web 2.0 type applications such as NearPod, GoogleDocs and Twitter enable learners to work together to complete a task or activity and this can be both in face-to-face or distant contexts. In the primary/elementary school setting it is more likely pupils will be situated in real-time face to face contexts but applications such as these still support high levels of sharing and interaction such as the collaborative production of a narrative in which pupils work in groups using an application like GoogleDocs on their mobile device to draft and refine the text together. It is likely more applications and tools will emerge to support 
this form of collaborative learning and early examples such as NearPod have already demonstrated how traditional forms of teaching (e.g. the whole-class presentation) can be extended and enhanced on a mobile device by enabling feedback from users during the presentation which can also be undertaken remotely in non face-to-face contexts.

\section{Learning in authentic settings and contexts}

Mobile technologies work in a variety of different contexts which include the formal classroom, but extended into informal contexts such as museums and field-trips and the playground or the home. The mobile device itself acts as a mediating technology enabling pupils to access and organise their work seamlessly between different contexts.

In the classroom itself mobile technologies offer opportunities for making both the setting and the tasks or activities which are designed by the teacher more authentic and realistic. The appropriate use of games such as Minecraft, for example, have been shown to create a more realistic context for pupils when they are working on a topic about real-world problems such as environmental issues or in the case of history, a recreation of a disaster such as the Titanic (Burden, et al, 2012). Additionally, individual access to the internet through a mobile device allows the teacher to design more realistic tasks for pupils which approximates more closely to real-world events and situations. Once such example is the use of apps which track and collate real time data from the world such as earthquakes and volcanic eruptions (e.g. QuakeSpotter) enabling pupils to observe and analyse genuine data virtually in real-time.

\section{Learning in informal settings}

The term informal learning refers to learning that occurs outside of the school in settings that are designed for education and enjoyment. Some of the venues that this term applies to includes museums, zoos and art galleries. The ways that mobile devices can be used are varied. In one example called 'mystery at the museum' a small group of pupils collaborated to solve a mystery inside the museum, interacting through mobile devices (Cabrera, et al, 2005). The pupils each received a different piece of information via their device and then were required to come together and solve the mystery. Whilst the findings indicated favourable learning outcomes one of the concerns of the project authors was that they were designing an activity that focused pupils" attention on the interactivity with each other rather than the museum exhibits. Whilst the pupils in the project were high school pupils this activity could be easily adapted for primary school pupils.

One of the liberating features of the mobile technologies is their portability which allows them to be taken into the field to support pupils' gathering of data which can then be used back in the classroom to further their understanding of the focus of the investigation. In this way the devices support pupils' learning in authentic settings. In one example pupils used handheld computers to 
facilitate their learning on environmental issues using the 3Rs ('Reduce, Reuse and Recycle') in a Singapore primary school. Using handheld computers throughout a field trip, the year 4 pupils investigated "how wastes are produced and what impact 3Rs can have on protecting the environment. The handheld computers were used to support, guide, and extend pupl thinking process within and out of classroom" (Chen, et al, 2008, p 321).

Whilst one of the affordances of mobile technologies allows pupils to collect the data, edit it and combine it to create final projects on the one device, this is not always possible or desirable. Pupils should, where it is appropriate, "be able to create, access and manipulate their field data across a range of computer systems" (Stewart, et al, 2009). The increase of online spaces and the ease of sharing content between devices is much easier with cloud computing now available.

Other ways that pupils can use mobile devices in informal learning settings are that they can capture images or video using a built in camera. The use of QR codes or virtual software can provide extra information on exhibits in the form of text, speech, images, video or graphic overlays. Pupils could download interactive maps that could then be used to guide their experiences in the museum. They could also be alerted to any events that were occurring prior to the event via the mobile device. They could use them as communication tools to keep in contact with their teachers as a security measure. These are only a few of the ways that mobile devices can support learning in informal settings. What is important though as suggested in the mystery in the museum is that that these devices enhance rather than inhibit the experience in the settings. This will require careful pedagogical consideration by both informal educators and teachers.

\section{Learning by making and constructing with mobile devices}

Knowledge construction is a powerful and motivating form of learning for primary age pupils and mobile devices support a variety of activities which enable pupils to experience the process of knowledge production and dissemination in a number of different forms, hence supporting differentiation and variety. Until recently, for example, the opportunity to experience the production of a video or even a movie was relatively rare for primary age pupils requiring access to specialist equipment (e.g. video cameras, sound recording kit, editing facilities) knowledge and understanding which was beyond the scope of most teachers and pupils, certainly on a daily or more frequent basis. The advent of mobile technologies featuring relatively sophisticated video, audio and editing capabilities have brought video production into the classroom itself enabling pupils to film and edit on the device itself. Initial investigations of these technologies suggest the production of short movie trailers (e.g. iMovie trailers) based around a small number of templates are extremely popular with teachers and pupils who produce them to summarize a particular topic or to illustrate their understanding of a particular concept or idea (Burden, et al., 2012). As the technology becomes more prevalent and the novelty value of using templates wane, teachers also recognise other opportunities to use these multi-modal affordances of mobile 
technologies to support knowledge construction. They are used, for example, to capture and describe a process or sequence such as a performance in physical education (Maher, 2013) or dance where pupils record their own performance to analyse later. Some teachers encourage pupils to use their mobile device to capture processes in their learning such as an experiment in science or a particular technique in drama which they can return to later to watch and learn from.

A wide variety of apps and tools support similar form of multi-modal knowledge construction in which pupils take the lead in production. Animation is a good example with a wide variety of apps such as Puppet-Pals and Toontastic which enable pupils to construct semi-professional outputs on the device itself. The same is true for knowledge and concept maps (e.g. Popplet) which allow pupils to generate multi-modal representations to demonstrate their understanding of a topic which can then be shared or even edited with other learners.

Finally it is also possible for pupils to record and annotate directly from their mobile device, producing a screencast or mini-video recording which combines video screen shots with additional content such as a voice over and annotations from the pupl. A variety of apps have emerged which support this kind of knowledge construction (e.g. Explain Everything; Show Me, etc) and initial feedback from teachers indicates they are being used in many different and exciting ways to support learning. One of the most promising may be the use to support feedback both to and from the pupl. In one documented example a teacher has used the app Explain Everything to encourage pupils to articulate how they tackled a particular problem or question (e.g. a complex maths equation) by writing down the process and explaining their thinking verbally as they do so. The results are extremely informative for the teacher who is able to identify any misconceptions and misunderstanding when and where they occur. However, the deeper value of such activities may lie with the pupl who is able to replay and reconsider their own thinking (and the feedback from the teacher if it is included) in a manner which makes thinking more visible (Richards, 2012).

\section{Logistical considerations in using mobile technologies}

When deciding to go down the path in using mobile technologies in schools considerations need to be taken into account and a number of decisions need to be made. It is important that a wholeschool approach is adopted so that resources are shared which can save money and maximise learning opportunities.

If possible, one of the resources that should not be shared is the mobile device and should 'belong' to one pupil (Burden, et al, 2012). The decision who owns the device needs to be made in conjunction with the school community and will reflect in part, the socio-economic standing of the community. In one Sydney private school observed for a study by one of the authors, 
iPads were purchased by the parents and were password protected by the parents so that the pupils were unable to download games, which would potentially distract pupils in the class. The school set $\$ 100$ as the maximum parents would be asked to pay for apps.

It also important to consider how to protect the devices from being damaged and what happens if they get damaged. Having protective covers is especially important. There are a number of companies now who manufacture cases for mobile devices so if they get dropped the risk of damage is minimised. If the devices do get damaged or malfunction it is important that a system is in place so that so that they can be repaired and returned to the classroom quickly. It is also worth considering having insurance for the devices to cover damage.

Some suggestions put forward by Goodwin (2012) which she calls logistical considerations include:

- if every pupl has a mobile device, how will they identify theirs?

- how will pupils personalise their devices?

- how will the devices be stored and charged?

- how often will they need to be charged?

If the devices do not need to be charged every day it is possible that charging stations can be shared which can cut down significantly on costs.

Another important consideration is taking the device on excursions. In a study conducted by one of the authors pupils took their iPads on a three day camp which included a visit to a museum. One of the findings was that whilst the iPads did enable a lot of learning to occur, pupils found them unwieldy when they wanted to engage in activities that required the use of both hands. A very light back pack would have allowed pupils to secure the devices when not needed. It is also worth considering the type of excursion and if the use of mobile technologies is best suited for the activities that will occur. Excursions that involve a lot of physical activity and not well suited to the use of mobiles. Finally, it should be noted that Internet enabled mobile devices, like the iPad, raise issue relating to privacy and e-safety and younger pupils will need careful guidance and advice in order to ensure they are used in a responsible and safe manner. There is insufficient space available to explore this in any more detail in this chapter but you will find

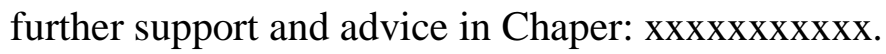




\section{Task 4: Designing a mobile learning activity}

Select one of the practical strategies for using mobile devices covered in this section and design your own activity around this strategy to use in your classroom. Try to evaluate the learning which occurred in this activity using the models explained earlier in the chapter..

\section{Conclusions}

The use of mobile technologies, both in the classroom and beyond, repositions the role of the teacher. In a traditional classroom the teacher has generally been the sole provider of knowledgethe gate keeper. Using mobile devices, a greater number of experts can be called upon to supplement the knowledge of the pupils and to provide for different types of expertise. This expansion of experts allows new learning opportunities for both the pupils and the teacher which allows for a community of learners to be created. Through this, teachers are able to model the learning process to pupils.

Access to mobile technologies also repositions the role of the pupl in terms of their access to sources of knowledge and their ability to act more independently. Ubiquitous access to the Internet through these devices enable pupils to locate information independently although this raises many questions about digital literacy such as their ability to handle information in a critical manner. Pupils are potentially liberated from the physical boundaries of their own classroom when they use mobile devices which offer greater amounts of choice about where, when and at what pace learning occurs (Kearney, et al 2012; Burden et al., 2012).

The use of mobile devices requires that the curriculum be redefined. What constitutes the 'place of learning' is no longer the same. When learning takes place alters so that learning out-of-school hours influences in-school learning. Who is involved in the learning process changes and new ways of collaboration are possible. These changes mean a more fluid understanding of the curriculum is required to ensure that the benefits of the devices are being realised. It is important that a whole-school approach in relation to the curriculum is set in place to ensure that staff members are being trained around their use and resources are being provided.

In considering the use of mobile technologies into the classroom, it is important that teachers have a clear understanding of how to manage the devices. Clear expectations need to be put in place for pupils, parents and the teachers. As learning requires a range of experiences it is important to consider when these devices will be used, for what subjects, and how they interplay with other ways of learning. Allowing pupils to use the devices at home is important so when these go home, who can add apps and other content are all important issues that need to be communicated. 
Finally, the role of parents and other significant adults outside of school are foregrounded when pupils use mobile devices for learning, particularly if the device is a personal one which is available to pupils beyond the school itself. Pupils can continue their work more seamlessly when it is digitised and available on a mobile device and this may help to bridge the divide between home and school with parents taking on a more overtly educative role with their children. Some of the early case studies in mobile learning have reported interesting and potentially valuable learning gains, both for the pupl and the parent, when the device is used as a portal for sharing and explaining what the pupl is doing in school. It remains to be seen if schools will also recognise these gains as opportunities to re-conceptualise where the boundaries between formal and informal education now lie in the era of pervasive and ubiquitous access to technology of this nature.

\section{Further reading}

Kukulska-Hulme, A., Sharples, M., Milrad, M., Arnedillo-S’anchez, I., And Vavoula, G. (2009). Innovation in mobile learning: A European perspective. International Journal of Mobile and Blended Learning, 1, 1: 13-35.

$\mathrm{Ng}$, W. (2011).Mobile technologies and handheld devices for ubiquitous learning: Research and pedagogy. Hershey, PA: IGI Global.

\section{Additional Resources and websites}

Educational Technology and Mobile Learning. A resource of educational web tools and mobile apps for teachers and educators. http://www.educatorstechnology.com/

\section{References}

Burden, K., Hopkin, P., Male, T., Martin, S., and Trala, C. (2012). iPad Scotland Evaluation Report, The University of Hull: Hull. Available online at: https://www.academia.edu/3795954/iPad_Scotland_Evaluation_2012. Accessed 08.02.2014.

Johnson, L., Adams, S., and Cummins, M. (2012). The NMC horizon report: 2012 K-12 edition. Austin, Texas: The New Media Consortium.

Cabrera, J. S., Frutos, H. M., Stoica, A. G., Avouris, N., Dimitriadis, Y., Fiotakis, G., and Liveri, K. D. (2005). Mystery in the museum: collaborative learning activities using handheld devices. In Proceedings of the 7th international conference on Human computer interaction with mobile devices \& services (pp. 315-318). ACM.

Chen, W., Tan, N. Y. L., Looi, C. K., Zhang, B., and Seow, P. S. K. (2008). Handheld computers as cognitive tools: Technology-enhanced environmental learning. Research and Practice 
in Technology Enhanced Learning, 3, 3: 231-252.

Goodwin, K. (2012). Use of tablet technology in the classroom. State of New South Wales, Department of Education and Communities, 2012. Available online at: http://rde.nsw.edu.au/files/iPad_Evaluation_Sydney_Region_exec_sum.pdf. Accessed 14.7.2013.

Higgins, S., Xiao, Z., and Katsipataki, M. (2012). The Impact of Digital Technology on Learning: A Summary for the Education Endowment Foundation. Sutton Trust

Kearney, M,. Aubusson, P., and Schuck, S., Burden, K. (2012). Viewing Mobile Learning from a Pedagogical Perspective. ALT-J Research in Learning Technology. Vol 20

Kearney, M., and Maher, D. (2012). Mobile learning in maths teacher education: Driving preservice teachers' professional development. Australian Educational Computing 27, 3: 78-86.

Kinash, S., Brand, J., Mathew, T., and Kordyban, R, (2011). Uncoupling mobility and learning: When one does not guarantee the other. Learning and Teaching papers. Paper 25. Available online at: http://epublications.bond.edu.au/tls/25. Accessed 15.7.2013

Koole, M., McQuilkin, J., and Ally, M. (2010). Mobile learning in distance education: Utility or futility? Journal of Distance Education, 24, 2: 59-82.

Kukulska-Hulme, A., and Traxler, J. (2005). Mobile learning: A handbook for educators and trainers. Routledge: New York.

Leadbetter, C. (2005). Learning about personalisation: How can we put the learner at the heart of the education system? Available online at: https://www.education.gov.uk/publications/eOrderingDownload/DfES-0419-2004.pdf. Accessed 24.8.13.

Luckin, R., Bligh, B., Manches, A., Ainsworth, S., Crook, C., and Noss, R. (2012) Learning: The Proof, Promise and Potential of Digital Education. Nesta.

Madden, M., Lenhart, A., Duggan, M., and Cortesi, S. (2013). Teens and technology. Pew Research Center. Available online at: http://www.pewinternet.org/Reports/2013/Teens-and-Tech.aspx. Accessed 25.8.13.

Maher, D. (2013). Pre-service primary teachers' use of iPads to support teaching: Implications for teacher education. Educational Research for Social Change, 1, 3: 48-63

Merchant, G. (2007). Mind the gap(s): Discourses and discontinuity in digital literacies. Elearning 4, 3: 241-254.

Motiwalla, L.F., 2007. Mobile learning: A model and evaluation. Computers \& Education, 49, 3: 581-596.

Pachler, N., Cook, J., and Bachmair, B. (2010). Appropriation of mobile cultural resources for learning. International Journal of Mobile and Blended Learning, 21:1-22

Richards, R (2012) Screencasting: Exploring a middle school math teacher's beliefs and practices through the use of multimedia technology. International Journal of Instructional Media, 39, 1: 55-67.

Stewart, K., Thompson, K., Hedberg, J., and Wong, W. (2009). Using technology to support quality learning for school activities involving field studies. Architectures for distributed and complex m-learning systems: Applying intelligent technologies. Hershey: IGI Global.

Teall, E., Wang, M. and Callaghan, V. (2011). A Synthesis of Current Mobile Learning Guidelines and Models. In World Conference on E-Learning in Corporate, Government, 
Healthcare, and Higher Education 2011. Honolulu, Hawaii, USA: AACE, pp. 443-451. Available online at: http://www.editlib.org/p/38749. Accessed 10.11.13.

Yahya, S., Ahmad, E. A., Jalil, K. A., and Mara, U. T. (2010). The definition and characteristics of ubiquitous learning: A discussion. In International Journal of Education and Development using Information and Communication Technology (IJEDICT).

Vavoula, G., Sharples, M., Rudman, P., Meek, J., and Lonsdale, P. (2009). Myartspace: Design and evaluation of support for learning with multimedia phones between classrooms and museums. Computers \& Education, 53, 2: 286-299.

Wishart, J., and Triggs, P. (2010). Museum Scouts: Exploring how schools, museums and interactive technologies can work together to support learning. Computers and Education, 54, 3: 669-678. 